\title{
Herbal medicine in new era
}

\begin{abstract}
Herbal medicine is the precursor of modern medicine and drug development. It is still the useful knowledge and routines to foster new therapeutics in the clinic and useful drugs against new diseases. This article brings a glimpse of this special medical discipline. Comparisons between herbal medicine and modern pharmaceutical/ medicines are provided.
\end{abstract}

Keywords: herbal medicine, drug development, cancer treatment, clinical therapy
Volume 3 Issue 4 - 2019

\author{
Da-Yong Lu,' Ting-Ren Lu \\ 'School of Life Sciences, Shanghai University, China \\ ${ }^{2}$ College of Science, Shanghai University, China
}

Correspondence: Da-Yong Lu, School of Life Sciences, Shanghai University, Shanghai 200444, China, Email ludayong@shu.edu.cn

Received: June 14,2019| Published: July 02, 2019

\section{Introduction}

\section{Medical significance}

Natural components and drugs play huge role in large population of infectious patients. To strengthen this argument, several wellknown modern drugs are exemplified herein. For example, the most effective antibiotics (penicillin, streptomycin or cephalosporin) are all-natural resource chemical products and drugs worldwide. They are more useful than a series of synthetic antibiotics (sulphonamide) developed before penicillin. Many natural products and drugs are widely utilized as anti-diabetic agents and different types of anticancer drugs worldwide. In addition, digitoxin (a natural chemical drug) is used against fatal heart symptoms. These kinds of drugs play key roles in the treatment of many diseases and face new challenge for the generations to come. ${ }^{1,2}$

\section{Significance of herbal medicine}

Medicinal chemistry and pharmacological efforts to develop drugs is a complicated process due to drug screening convention limitation. As a result, herbal medicine tradition must be introduced.

\section{Methods}

\section{General scenario of herbal medicine}

Herbal medicine has a long history of evolution in styles and practice worldwide. In its early stage, herbal or animal medicines were widely utilized over many different countries, including Greece, as allopathic medicine, Ayurvedic medicine in India and traditional Chinese medicine. ${ }^{3-7}$ Yet, most of such countries lost this tradition. China still maintains herbal medicine in modern day because it reserves many ancient medical books by leading publication systems in the ancient world.

China has a long reputation of treating a wide variety of diseases by herbal medicine. This type of medical practice dates back at least 2000 years. Several earliest medical books were published between $100 \mathrm{BC}$ to $1900 \mathrm{AD}$. It has been successfully managed for large endemics since the era of Zhong-Jin Zhang (AD150-219) in China. According to theory of traditional Chinese medicine (TCM), human diseases can be categorized with patient's imbalance between "YinYang". TCM doctors try to combat these patterns of symptoms (like fever, cough and immune deficiency) by strengthening, modulating and offsetting these damaged "Yin-Yang" in human bodies by formulated herbals. ${ }^{8-11}$ The formulated herbal medicines contain large components of chemical admixtures and somewhat like modern drug combinations in western styles of therapeutic philosophy.

\section{TCM for various diseases}

TCM has its advantageous and disadvantageous to manage diseases. The advantages for TCM can be both acute disease (like microbial or viral infection) and chronic diseases (like cancer, diabetes, obesity, bone diseases and metabolic symptoms). ${ }^{12-24}$

Apart from different disease types, some disease symptoms are also within the range of TCM. For example, Ma-Xing-Shi-Gan-Tang is prescribed to remove toxic heat obstruction in the lungs of infected patients. These items of herbal formulas are historically used as the preventive measures to attack widespread epidemics like avian flu or Ebola epidemics in modern days. ${ }^{25-31}$

In viral epidemics, a series of disease risk-factor is somewhat like "Helium--liqi" in ancient Chinese nomination in medical literatures. "Helium" is a high contagious disease that belong to outside invaders. The character of Heliumis a process somewhat like bacteria or viral infection in symptoms of high infectivity, sudden climate related. Hygiene and isolation are workable options for disease managements in the same time.

Diabetes (Xiaoke Diabetes, a Chinese definition of diabetes) characterized with symptoms of thirsty, hungry and urination has been noticed over two thousand years in China. ${ }^{32-34}$ In the second half of last century, type 2 diabetes mellitus (T2DM) was gradually recognized as a major public healthcare problem worldwide. ${ }^{32-34}$ The incidence of T2DM in China and other developing and developed countries has been growing due to incomplete knowledge about causality, pathogenesis, antidiabetic therapeutics. ${ }^{35-41}$ Despite some therapeutic advances, T2DM treatments are not widely successful in clinical trials. Currently, a lot of herbs and natural products, even natural chemical drugs are first-line anti-diabetic drugs for patients with T2DM.

\section{Results}

\section{Herbal medicine practice}

TCM treats patients according to their abnormal symptoms and disease categorizations (majorly outside invaders and body-organ 
dysfunction) (Figure 1) many pathogenic symptoms of serious diseases such as pulmonary obstruction, high fever and unconscious can be relieved by different formulae of herbal medicines.

Modern medical practice calls for new drug developments and clinical applications. Although few herbal medicines have been published for specific viruses such as Ebola, avian flu, Zika therapeutics in ancient Chinese books, a great number of new chemical ingredients from microbial or plants in western countries have been available for modern diseases. Previously, ingredients from microbial or plants in western society were very expensive. Now, these ingredients are much cheaper due to technical advancements, especially extraction methods. Next generations of cutting-edge technology will enable us quick development of natural chemical drugs. Figure 1 depicts general routine of TCM in the clinic that may help western doctors understand Chinese medicine with a closer look.

\section{Patients seeking medications Traditional diagnostics}

(Inquiry, listening, watching and pulse sensations) Pathogen-induced physiological imbalance

(Five organs and six physiological entities) Different types of therapeutic recipes

(From thousands of fixed combination recipes) Individualized Chinese medicines

Figure I Diagrams of traditional Chinese medicines therapeutic routes.

In TCM, formulae of herbal medicine is presented in different forms and dosage-different formulae (Fangji, prescription). Different herbal formulae can be used to treat one disease or symptom. However, one herbal formula can be used for different diseases or symptoms in a similar clinical situation. It may be regarded as tricky in western philosophy. But it is a usual strategy in TCM practice. Next generation of cutting-edge technology (genomic/epigenetic and molecular basis) will enable us quick development of modern pharmaceuticals. All these medical explorations and drug development must go through robust experimental and clinical verification.

\section{Current drug developments}

Currently, many different types of modern drug developments need huge funds to support. Drug producer is a pillar industry for a small number of world-leading countries worldwide. ${ }^{42-47}$ Nevertheless, drug discovery, development and manufacture have been a bottleneck stage over the past two decades. The constantly declining of drug successful rates in clinical evaluation have multiple causes, such as higher therapeutic demanding for new drugs as well as rising cost for cutting-edge equipment utility. Therefore, a great amount of money needs to be paid for drug screening, experimental mechanistic studies and systematic clinical evaluations. Despite greater expenses in drug developing countries, cancer therapies only improve slightly, especially for cancer metastasis treatments. Thus, it is necessary to learn from TCM in drug developments.

\section{Herbal medicine in world markets}

Overall, herbal medicine must be translated into modern drug developments and clinical evaluations. In the past, a great amount of work for natural chemical drugs has been undergone. However, most of these efforts and processes are based on western medical philosophy. Almost half chemical drugs in western markets are coming from natural microbial, plant and animals. Despite a lot of successes, many obstacles still need to overcome. Yet, currently no specific drug developmental system has been widely used and wholly dependent upon. Updating drug development routine is an inevitable avenue.

\section{Drug development transformation}

Facing the situations of high risks, cost surge and low productivity in modern drug developments, creative studies for science and technology can provide such opportunity and unprecedented insights into powerful therapeutics against many new diseases, high mortality and new pathogens in TCM.

The advantages of natural chemical drugs comparing with synthetic chemotherapeutic agents are low toxicities and drug cocktail (mixture ingredients). The drug combinational rules widely used in China may play pivotal roles for a variety of new lethal virus infections and latestaged cancer management, which needs good paradigm propagation worldwide. ${ }^{48-58}$ To ensure a smooth progress of natural chemical drug developments, new ideas and perspective must be explored. Some medical articles and books can also attract the attention and get quick feedback in the clinic.

\section{Discussion}

\section{Paradigm introductions for viral-infection, diabetes and cancer}

Since virus-induced human mortality acts differently (Ebola or avian flu with quick human mortality and HIV or Zika with slow pathogenesis processes), drug evaluative routines, disease pathologic discovery and drug mechanisms must be carried out by alternative ways. For Ebola or avian flu treatment, quick disease management or viral proliferative inhibition is the key. Yet for HIV or Zika infections, managing damaged human organs or physiological entities (immune rebuilding or cerebral damage protection) is more important to understand. ${ }^{59-72}$

Similarly, tumours are categorized with different subtypes and pathologic stages. This pathologic variation is very suitable for individualized therapeutics such as TCM, drug sensitivity testing and pharmacogenetic approaches (Table 1). ${ }^{73-81}$

The key quality of different chemotherapeutic agents is the balance between therapeutic responses and toxicities and risks, displaying as a therapeutic index gain. Many currently incurable diseases, such as HIV-infections in humans may come from shortage of effective natural chemotherapeutic drugs and fundamental knowledge of patho-therapeutic relationship. The only limitation of natural chemotherapeutic agents was the cost of drug purification and natural product cultivation and collection. However, with the modern 
purification and cultivation technology, natural chemical agents will be much cheaper in the future. Owing to this advancement, a growing number of natural chemical drugs may get into the markets. There will be plenty of herbal products in future pharmaceutical markets.

Table I Patho-therapeutic relations in TCM

\begin{tabular}{|c|c|c|}
\hline $\begin{array}{l}\text { Disease } \\
\text { causality }\end{array}$ & Main symptoms & Therapeutics \\
\hline \multirow[t]{4}{*}{ Wind evil } & Sudden \& movable & Prevent wind/expel wind \\
\hline & $\begin{array}{l}\text { Different types of } \\
\text { colds }\end{array}$ & Fang-fen \\
\hline & Movable headache & Jin-jie \\
\hline & Urticaria/nettle-rash & Leaf of bamboo \\
\hline \multirow[t]{5}{*}{ Cold evil } & Pain \& stasis & $\begin{array}{l}\text { Warm \& circulation } \\
\text { promotion }\end{array}$ \\
\hline & $\begin{array}{l}\text { Whole-body pains } \\
\text { and ache }\end{array}$ & Si-ni-tang \\
\hline & Immovable & Huang-qi \\
\hline & Solid cancers & Fu-zi \\
\hline & Circulation stasis & \\
\hline \multirow[t]{4}{*}{$\begin{array}{l}\text { Wet evil / } \\
\text { damp evil }\end{array}$} & Phlegm \& Damp & $\begin{array}{l}\text { Clearance \& anti- } \\
\text { inflammation }\end{array}$ \\
\hline & $\begin{array}{l}\text { Gastro-intestinal } \\
\text { symptoms }\end{array}$ & Yi-yi-ren \\
\hline & Xiaoke (diabetes) & Di-huang \\
\hline & Phlegm-damp syndror & (cough) \\
\hline \multirow[t]{5}{*}{ Heat evil } & $\begin{array}{l}\text { Heat-related } \\
\text { symptoms }\end{array}$ & Expel heat \& stay cold \\
\hline & Fever & Yin-qiao \\
\hline & Sweat & Jing-yin-hua \\
\hline & Coma & Water melon \\
\hline & Unconsciousness & Shi-gao \\
\hline \multirow[t]{4}{*}{ Li-qi } & $\begin{array}{l}\text { Fever, infection \& } \\
\text { Deaths }\end{array}$ & Isolation and treatments \\
\hline & Fever & Qing-Hao \\
\hline & Diarrhoea & Ma-hua-san \\
\hline & Bleeding & \\
\hline
\end{tabular}

\section{Education and publications}

Though a great number of first line and second-line pure therapeutic chemical drugs such as campthothecine, harringtonine were discovered from herbal resources by western scientists, some of them were long reported in TCM literature. Medicinal chemists and pharmacologists worldwide are paying growing attention to from surveying TCM past and new literature. Although this literature is valuable for modern medicine, these TCM books are unpopular in normal medical universities worldwide, even in China. Limited courses of herbal medicine decrease the quality of clinical practice and drug developments until now.

\section{Comparisons in cancer treatments}

Cancer treatment by TCM is one hot spot in modern China. Many TCM hospitals in China have a special department of cancer therapeutics. TCM for cancer treatments has been positively reported in China. According to the principles of TCM, human bodies are balanced by fighting between inner upright strength and outside damaging air. Current principles of TCM therapies seeks therapy by strengthening upright air rather than expelling outside evils. Additionally, expelling exogenous wind-heat recipes are also used for cancer therapies by TCM.

There are two pathways of therapeutics-malignant targets and symptom relieving in TCM. Solid cancer is regarded as syndrome of blood stasis and phlegm-damp syndrome. To achieve phlegm-damp syndrome control, cancer patient symptoms and syndromes may be clinically treated. It is also manifested as survival benefits in cancer patients. Besides symptom ameliorating, TCM can sometimes play decisive roles in cancer treatments.

Apart from first-line anticancer drug, herbal or natural compounds can be used as assistant therapeutic agents to treat cancer growth, invasive and remote metastasis. These compounds are less cytotoxic in western medical encyclopaedia, such as curcumin or anthocyanins. In western countries, cancer assistant therapies include nutritional support, pain relieving, cardiovascular detoxication, antioxidants and many others. Though promising, cancer assistant therapies are not mainstreaming clinical cancer treatments in most western countries. At this stage of medical knowledge, the core of cancer assistant therapeutics is to combine cytotoxic anticancer drugs and assistant therapeutic agents (mostly natural chemical or biological compounds). Generally, drug combination for cancer is as good as therapeutic combination paradigm for HIV (Table 2).

Table 2 A comparison between western therapy and TCM practice

\begin{tabular}{|c|c|c|}
\hline Categories & $\begin{array}{l}\text { Western } \\
\text { therapy }\end{array}$ & Chinese therapy \\
\hline Diagnostics & Instruments & $\begin{array}{l}\text { Inquiry, listening, watching and } \\
\text { pulsing }\end{array}$ \\
\hline Drug numbers & $\begin{array}{l}\text { I-3 drugs } \\
\text { commonly }\end{array}$ & 3-8 herbs \\
\hline Suitability & Acute disease & Chronic disease \\
\hline Toxicity & Various & Only some toxic drugs \\
\hline $\begin{array}{l}\text { ADME (such as } \\
\text { P450) }\end{array}$ & $\begin{array}{l}\text { Commonly } \\
\text { available }\end{array}$ & Difficult to undergo until now \\
\hline Costs & $\begin{array}{l}\text { High (especially } \\
\text { new drugs) }\end{array}$ & $\begin{array}{l}\text { Generally low and easy } \\
\text { accessed }\end{array}$ \\
\hline
\end{tabular}

\section{Future direction}

\section{Ideology promotion}

The quality of natural drug developments can be improved by a deeper understanding of herbal medicine practice and theories. 
Research on herbal medicine will translate eastern therapeutic measures into western medical paradigms. Currently, most people in China believe that natural herbs have no toxicity. This view has no scientific basis. But many natural chemotherapeutic agents generally show less toxicities comparing with synthetic chemical agents at the same therapeutic ranges. It appears that nature is the greatest medicinal chemist in this very planet.

\section{Therapeutic study for new diseases}

Zika virus epidemic in America is an emerging medical crisis that is receiving growing body of global attention. Good Zika knowledge must be established as early as possible. Innovation of Zika therapy by TCM or natural chemotherapeutic agents may be useful in the future. We suggest that TCM study may create workable solution on Zika pathogenesis and therapeutics in the future.

\section{Genomic study}

Apart from general pathway for pathogenesis and therapeutics, new generations of techniques may be borrowed for TCM and natural chemical drug developments, such as cancer genomic study and HIVintegration into human genomes. But these issues face ethical debates and regulatory challenges.

\section{Treatment of metastasis by TCM}

Neoplasm metastasis is a multi-step and multi-level phenotype that is responsible for $90 \%$ cancer mortality in the clinic. ${ }^{82-87}$ Many different states of metastatic cells (ever-changing character) in wideranges of human organs and tissues are now known as neoplasm plasticity. ${ }^{85-87} \mathrm{~A}$ lot of currently licensed drugs only target a narrow range of these various metastatic states. Nevertheless, TCM is famous for solving whole-body disease and body and organ imbalance. The question of whether TCM can be an alternative solution for neoplasm metastasis is open.

In TCM practice, doctors commonly change their therapeutic strategy according to past medication and cure patients in a short period of time. This phenomenon is not common in western treatments. Many therapeutic drugs are required to treat patients lifelong. Balanced therapeutics of these two systems may be promoted in disease treatments. (Figure 2).

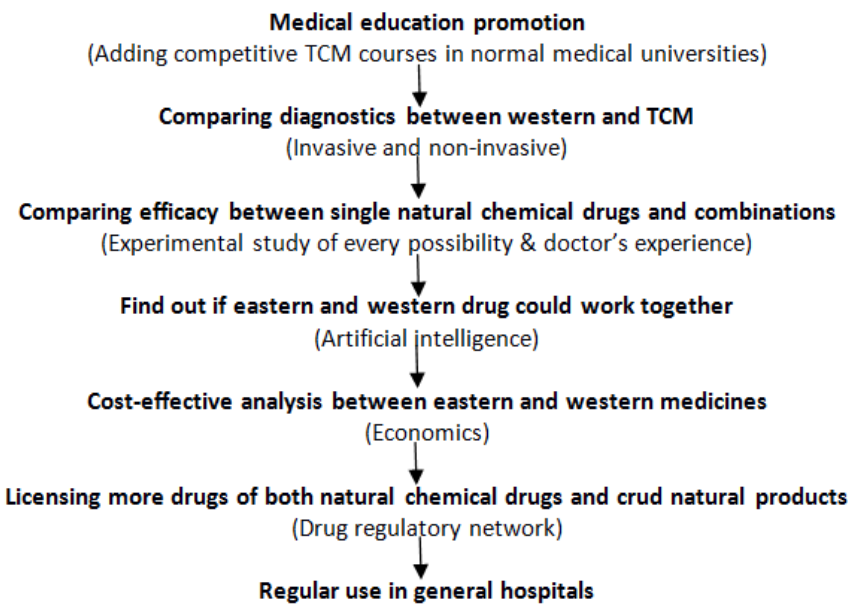

Figure 2 Roadmap for the promotion of natural chemical drugs andTCM.

\section{Conclusion}

Herbal medicine and natural chemical drugs are interrelated for both basic and practical values. Creative ideas and scientific approaches can promote medical tools against dangerous diseases. Herbal medicine knowledge must be established for high-quality and wider-range drug development and clinical applications. ${ }^{88-91}$ To achieve this goal, integration of western and eastern medical practices is a top priority.

\section{Acknowledgments}

None.

\section{Conflicts of interest}

The authors declare there is no conflict of interest.

\section{References}

1. Ali I, Saleem K, Uddin R, et al. Natural products: human friendly anticancer medications. Egypt Pharm J (NRC). 2010;9:133-179.

2. Lu DY, Lu TR, Lu Y, Sastry N, Wu HY. Discover natural chemical drugs in modern medicines. Metabolomics. 2016;6(3):181.

3. Pattanayak S. Alternative to antibiotics from herbal origin-outline of comprehensive research project. Current Pharmacogenetics Personalized Medicine. 2018;16(1):9-62.

4. Parasuraman S. Herbal drug discovery: challenges and perspectives. Current Pharmacogenetics Personalized Medicine. 2018;16(1):63-68.

5. Zhang ZJ. Cold factors and treatments. People's Medical and Public Health Publication. Beijing, PR China, 2005.

6. Li SZ. Compendium of Materia Medica.

7. The Emperor's Medical Experience, Questions and Answer.

8. Lu DY, Lu TR, Wu HY. Treatment of influenza virus infections with Chinese medicine. Adv Pharmacoepidemiology Drug Safety. 2012;1:e104.

9. Lu DY, Lu TR, Wu HY. Avian flu, pathogenesis and therapy. Anti-Infective Agents. 2012;10(2):124-129.

10. Lu DY, Lu TR, Wu HY, et al. HIV/AIDS curable study, new forms of therapeutic trinity. Rec Pat Antiinfect Drug Discov. 2018;13(3):217-227.

11. Lu DY, Wu Hy, Yarla NS, et al. Ebola therapeutic study and future trends. Infect Disorder Drug Targets. 2019;19(1):17-29.

12. Hu B, Du Q, Shen KP, et al. Principles and scientific basis of traditional Chinese medicine in cancer treatment. J Bioanal Biomed. 2012;S6:005.

13. Alam F, Islam MA, Kamal MA, et al. Updates on managing type 2 diabetes mellitus with natural products, towards antidiabetic drug developments. Curr Med Chem. 2018;25(39):5395-5431.

14. Lu DY, Che JY, Yarla NS, et al. Diabetes prevention and treatments, a specific topic for modern medicines. J Metabolic Syndrome. 2017;8(3):231.

15. World Health Organization. WHO, Obesity and overweight. 2018.

16. Lu DY, Che JY, Wu HY, et al. Obesity, risks and managements. Metabolomics. 2018;8(1):e155.

17. Lu DY, Che JY, Lu Y, et al. An overview of obesity. Metabolomics. 2018;8(2):200.

18. Lu DY, Che JY, Lu TR, et al. Pathology and treatments of obesity. Trends in Medicine. 2018;8(5):157.

19. Lu DY, Che JY, Yarla NS, et al. Bone disease recovery strategies, An overview. EC Orthopaedics. 2019;10(1):1-3. 
20. Lu DY, Che JY, Yarla NS, et al. Human obesity, pathological and therapeutic advances. EC Pharmacology \& Toxicology. 2019;7(4);231238 .

21. Aggarwal R, Jain SK. Obesity and metabolic phenotypes. EC Diabetes \& Metabolic Res. 2017;1(1):11-12.

22. Rafael H. Therapeutic methods against insulin resistance. J Endocrinol Metab. 2016;6(1):1-11

23. Lu DY, Che JY, Shen Y. Osteoporosis, importance for early diagnosis and treatment. EC Orthopaedics. 2018;9(9):624-625.

24. Lu DY. HIV/AIDS Treatments, Fight for a Cure. Germany: LAMBERT Academic Publishing; 2017:120.

25. Lu DY, Wu HY, Yarla NS, et al. HAART in HIV/AIDS treatments, future trends. Infect Disord Drug Targets. 2018;18(1):15-22.

26. Lu DY, Lu TR, Che JY, et al. Advances and shortcoming of HIV/ AIDS therapy. Innovations in Pharmaceuticals and Pharmacotherapy. 2015;3:511-518

27. Liu DF, Liu YL, Chen H, et al. Evaluation on the curative effect and safety of Chinese traditional medicine in treatment of mild a/hH1N1 influenza in sichuan area. Modern Preventive Medicine. 2011;38(2):338-343.

28. Zhou Ho, Tao LT, Xu HC, et al. Discussion on laws of traditional chinese medical treatment of H1N1 influenza based on cohort study. World Science and Technology. 2011;13(5):777-782.

29. Rumschlag-Booms E, Zhang HJ, Soejarto DD, et al. Development of an antiviral screening protocol: one-stone-two-birds. J Antivir Antiretrovir. 2011;3:8-10

30. Li YH, Yan QB, Yu KZ, et al. Study of the compound Chinese medicine against the anti-avian influenza virus. Scientia Agricultura Sinica. 2008;41(5):1511-1518

31. Lu DY, Lu TR, Wu HY. Zika therapy by traditional Chinese medicine, a new proposal. Adv Pharmacol Clinical Trial. 2016;1(1):103.

32. Lu DY, Che JY, Yarla NS, et al. Type 2 diabetes study, introduction and perspective. The Open Diabetes Journal. 2018;8:13-21.

33. Lu DY, Che JY, Yarla NS, et al. Type 2 diabetes treatment and drug development study. The Open Diabetes J. 2018;8:22-33.

34. Laroo H. The escalating incidence of late onset of diabetes II-strategies and remedies for use on a personal basis. EC Diabetes \& Metabolic Res. 2018;1(3):58-70.

35. Shamm Ahmad. Diabetes. An Old Disease, A New Insights. USA: Springer Science; 2013:485.

36. Lu DY, Che JY. Rethink of diabetes treatment and drug development. Cell \& Developmental Biology. 2014;3(2):e125.

37. Lu DY, Che JY, Yarla NS, et al. Type 2 diabetes, medical knowledge and pharmaceutical innovations. J Diabetology. 2017;1(1):1-3.

38. Singh A, Srivastav R, Randey AK. Protective role of Terminalia Chebula in streptozotocin-induced diabetic mice for wound healing activity. Brit J Medicine \& Medical Res. 2017;22(2):1-8.

39. Li GQ, Kam A, Wong KH, et al. Herbal medicines for the management of diabetes. Adv Exp Med Biol. 2012;771:396-413.

40. Imam K. Management and treatment of diabetes mellitus. Adv Exp Med Biol. 2012;771:356-380.

41. Wagh VD. Propolis: a wonder bees product and its pharmacological potentials. Adv Pharmacol Sci. 2013;2013:308249.

42. Merris J. Productivity counts-but the definition is key. Science. 2005;309(5735):726-727.
43. Gupta SC, Sung B, Prasad S, et al. Cancer drug discovery by repurposing: teaching new tricks to old dogs. Trends in Pharmacological Sciences. 2013;34(9):507-517.

44. Ali I, Haque A, Wani WA, et al. Analyses of anticancer drugs by capillary electrophoresis; a review. Biomedical Chromatography. 2013;27(10):1296-1311.

45. Ruggeri BA, Camp F, Miknyoczki S. Animal models of disease: Preclinical animal models of cancer and their applications and utility in drug discovery. Biochem Pharmacol. 2014;87(1):150-161.

46. Lu DY, Chen EH, Lu TR. Anticancer drug development, a matter of money or a matter of idea? Metabolomics. 2015;5(2):e134.

47. Lu DY, Lu TR, Zhu H, et al. Anticancer drug development, getting out from bottleneck. Int J Mol Biol. 2017;2(1):28-33.

48. Lu DY, Lu TR, Chen EH, et al. Anticancer drug development, system updating and global participations. Current Drug Therapy. 2017;12(1):3745

49. Lu DY, Cao JY, Xu B. Biological activities and clinical utilizations of harringtonine and homoharringtonine. Nat Product Res Development. 2000;12(5):70-73.

50. Prasad S, Tyagi AK. Traditional Medicine, the goldmine for modern drugs. Adv Tech Biol Med. 2015;3(1):e108.

51. Aravindaram K, Yang NS. Anti-inflammatory plant natural products for cancer therapy. Planta Med. 2010;76(11):1103-1117.

52. Yang G, Li X, Li X, et al. Traditional Chinese medicine in cancer care: a review of case series published in the Chinese literature. Evid Based Complement Alternat Med. 2012;2012:751046.

53. Manheimer E, Wieland S, Kimbrough E, et al. Evidence from the Cochrane collaboration for traditional Chinese Medicine therapies. $J$ Altern Complement Med. 2009;15(9):1001-1014.

54. Lo LC, Chen CY, Chen ST, et al. Therapeutic efficacy of traditional Chinese medicine, Shen-Mai San, in cancer patients undergoing chemotherapy or radiotherapy: study protocol for a randomized, doubleblind, placebo-controlled trial. Trials. 2012;13(1):232.

55. Li XQ, Ling CQ. Chinese herbal medicine for side effects of transarterial chemoembolization in liver cancer patients: a systematic review and meta-analysis. Zhong Xi Yi Jue He Xиe Bao. 2012;10(12):1341-1362.

56. Lu DY, Lu TR, Che JY, et al. Old theories revisited on cancer assistant therapy. Int J Medical and Health Sciences Res. 2014;1(5):50-57.

57. Pomerantz RJ, Horn DL. Twenty years of therapy for HIV-1 infection. Nat Med. 2003;9(7):867-873.

58. Goldberg DE, Siliciano RF, Jacobs WR. Outwitting evolution: fighting drug-resistant TB, malaria, and HIV. Cell. 2012;148(6):1271-1283.

59. Lu DY, Lu TR, Che JY, et al. New perspectives of HIV/AIDS therapy study. Recent Pat Antiinfect Drug Discov. 2014;9(2):112-120.

60. Cohen J. Animals show how Zika harms fetuses. Science. 2016;352(6287):752-753.

61. Pizza DMM, Loaiza AM, Montoya JFA, et al. A model for the risk of microcephaly induced by the Zika virus (ZIKV). Open Journal of Modeling and Simulation. 2016;4:109-117.

62. Lu DY, Lu TR, Chen XL, Ding J. Individualized cancer chemotherapy. In: Shoja MM, Agutter PS, Tubbs RS, et al. editors. Hypotheses in Clinical Medicine. USA: Nova Science Publisher; 2012:199-216.

63. Lu DY. Personalized cancer chemotherapy, an effective way for enhancing outcomes in clinics. UK: Woodhead Publishing, Elsevier; 2014:84 
64. Lu DY, Lu TR, Yarla NS, et al. Drug combination in clinical cancer treatment. Reviews on Recent Clinical Trials. 2017;12(3):202-211.

65. Lu DY, Chen EH, Wu HY, et al. Anticancer drug combination, how far we can go through? Anticancer Agents Med Chem. 2017;17(1):21-28.

66. Lu DY, Chen EH, Ding J, et al. Anticancer drug combinations, a big momentum is needed. Metabolomics. 2015;5(3):e139.

67. Putta S, Yarla NS, Peluso I, et al. Anthocyanins: Possible role as multitarget therapeutic agents for prevention and therapy of chronic diseases. Curr Pharm Des. 2017;23(41):6321-6346.

68. Alekshun MN, Levy SB. Molecular mechanisms of anti-bacterial multidrug resistance. Cell. 2007;128(6):1037-1050.

69. Lander ES. Initial impact of the sequencing of the human genome. Nature. 2011;470(7333):187-197.

70. Garraway LA, Lander ES. Lessons from the cancer genome. Cell. 2013;153(1):17-37.

71. Lu DY, Lu TR, Yarla NS, et al. HIV in human genomes and therapeutics. HIV: Current Research. 2017;2(1):121.

72. Lu DY, Lu TR, Yarla NS, et al. HIV in human genomes and related therapeutics. In: Da-Yong Lu, editor. HIV/AIDS Treatments, Fight for a Cure. Germany: LAMBERT Academic Publishing; 2017:68-76.

73. Rahimzadeh V, Bartlett G. Policies and practices of data-intensive primary care in the precision-medicine era. Internal Medicine Rev. 2017;3(9):114

74. Lu DY, Lu TR, Ding J, et al. Anticancer drug sensitivity testing, a historical review and future perspectives. Current Drug Therapy. 2015;10(1):44-55.

75. Volm M, Efferth T. Prediction of cancer drug resistance and implications for personalized medicine. Front Oncol. 2015;5:282.

76. Stransky B, Galante P. Application of bioinformatics in cancer research. An OMICS Perspective on Cancer Research. 2010:211-233.

77. Lu DY, Qi RX, Lu TR, et al. Cancer bioinformatics for update anticancer drug developments and personalized therapeutics. Rev Recent Clin Trials. 2017;12(2):101-110.
78. Garg PK. Potential of molecular imaging to advance molecular medicine. Cancer Stud Mol Medicine Open. 2017;3(1):e3-e4.

79. de Macedo JE. Knowledge of the molecular signaling pathways improves the chances of treatment of gastro-intestinal stromal tumors. Can Stud Mol Med Open. 2015;2(1):69-71.

80. Meyer UA. Pharmacogenetics-five decades of therapeutic lessons from genetic diversity. Nat Rev Genet. 2004;5(9):669-676.

81. $\mathrm{Lu} \mathrm{DY,} \mathrm{Lu} \mathrm{TR}, \mathrm{Xu} \mathrm{B}$, et al. Pharmacogenetics of cancer therapy: breakthroughs from beyond? Future Science OA. 2015;1(4):FSO80.

82. Talmadge JE, Fidler IJ. The biology of cancer metastasis: historical perspective. Cancer Res. 2010;70(14):5649-5669.

83. Valastyan S, Weinberg RA. Tumor metastasis: molecular insights and evolving paradigms. Cell. 2011;147(2):275-292.

84. Lu DY, Lu TR, Wu HY, et al. Cancer Metastasis treatments. Current Drug Therapy. 2013;8(1):24-29.

85. Nieto MA, Huang RY, Jackson RA, et al. EMT: 2016.Cell. 2016;166(1):2145 .

86. Lu DY, Lu TR, Xu B, et al. Cancer metastasis, a clinical dilemma for therapeutics. Current Drug Therapy. 2016;11(2):163-169.

87. Lambert, AW, Pattabiraman DR, Weinberg RA. Emerging biological principles of metastasis. Cell. 2017;168(4):670-691.

88. Smith RE, Tran K, Richards KM, et al. Dietary carbohydrates that modulate the immune system. Clinical Immunology, Endocrine and Metabolic Drugs. 2015;2(1):35-42.

89. Lu DY, Lu TR, Yarla NS, et al. Anticancer drug development, breakthroughs are waiting. Adv Pharmacology \& Clinical Trials. 2017;2(1):119.

90. Lu DY, Lu TR, Xu B, et al. Anticancer drug developments, challenge from historic perspective. EC Pharmacology \& Toxicology. 2018;6(11):922936.

91. Lu DY, Lu TR, Chen EH, et al. Keep up the pace of drug development evolution and expenditure. Cancer Rep Rev. 2018;2(5):165. 